\title{
POLITICA MINERA COMPARATIVA ENTRE ARGENTINA Y ECUADOR
}

\section{COMPARATIVE MINING POLICY BETWEEN ARGENTINA AND ECUADOR}

\author{
Mariana del Valle Tapia*
}

\section{Introducción}

Entre 2000 y 2015 se registraron las mayores fusiones y adquisiciones históricas del sector de la minería metálica en el mundo. Aproximadamente el 16\% del monto de esas operaciones tuvo como objetivo una empresa originaria de algún país de América Latina y el Caribe, y en el período mencionado se realizaron en la región operaciones por 78.000 millones de dólares (CEPAL, 2016, p. 13). Y si bien, se evidencia un claro liderazgo del Brasil, Chile, Perú y México como lugar de operaciones en la región, el presente artículo procura conocer la trayectoria minera de países que aún son incipientes en el negocio minero: Argentina a partir de la década de los noventa y Ecuador que se insertó al modelo minero internacional a partir del año 2008, a raíz de la generación de una política de estado orientada a la exportación de minerales metálicos.

El interés de las inversiones directas en la región se sostiene debido a que en América Latina y el Caribe se concentra un elevado porcentaje de las reservas mundiales de minerales metálicos: un 66\% del litio, un $47 \%$ del cobre, un 45\% de la plata, un 25\% del estaño, un 23\% de la bauxita, un 23\% del níquel y un 14\% del hierro, entre otros (CEPAL, 2016). Sin embargo, la existencia de recursos mineros, en lugar de ser una fuente de oportunidades en regiones donde se concentran altísimos niveles de pobreza y desigualdad social, se convierte en el origen de diversos conflictos y disputas por el control del territorio, por la captación de la renta minera o la vulneración de derechos humanos, entre otros.

Así, el Consenso de los Commodities promueve la implementación masiva de

\footnotetext{
* Phd(c) en Ciencias Sociales por la Facultad Latinoamericana de Ciencias Sociales - FLACSO - (Buenos Aires/Argentina).E-mail: lic.tapiamariana@gmail.com
} 
proyectos extractivos orientados a la exportación, generando un espacio de mayor flexibilidad en cuanto al rol del Estado, lo cual permitió el despliegue y coexistencia entre gobiernos progresistas, que han cuestionado el consenso neoliberal, con aquellos otros gobiernos que continúan profundizando una matriz política conservadora en el marco del neoliberalismo (SVAMPA, 2013a).

No obstante, al frenarse el crecimiento de China a partir del 2013, se produjo una caída en la demanda y los precios de los minerales. Como consecuencia, se han reducido las tasas de crecimiento y los ingresos fiscales de los Estados en la región. Bajo este contexto, la estrategia de los gobiernos de los países latinoamericanos fue promover políticas destinadas a continuar atrayendo inversiones extractivas a fin de mantener los actuales niveles de inversión, y de este modo, compensar la caída de los precios unitarios con un aumento importante de los volúmenes exportados, de manera que genere la misma cantidad de renta extractiva que en el pasado. No obstante, estas políticas debilitan aún más los frágiles estándares fiscales, ambientales y sociales en la región.

En el presente artículo, tiene por objetivo analizar las disparidades redistributivas desde la perspectiva estatal, considerando que se generan fracturas dentro del mismo Estado y en particular, en las relaciones intergubernamentales entre el Estado Nacional o central y las unidades administrativas donde se localizan los yacimientos mineros, independientemente del tipo de Estado (federal o unitario) por la captación y el control de la renta minera. Ello, debido a que el Estado Nacional asume un rol ambiguo y de permanente tensión entre la fusión de acumulación (inserción internacional) y la legitimidad estatal, en particular, ante la resistencia de los movimientos sociales frente a relaciones sociales desiguales, excluyentes y no democráticas que se presentan en los escenarios locales.

\section{Argentina y Ecuador: dos modelos de Estado en la región ante el negocio mega minero global}

La República Argentina adopta para su gobierno la forma representativa republicana federal, según lo establece su Constitución Nacional ${ }^{1}$, por ello se divide política e institucionalmente en tres niveles de gobierno: nación, provincias y municipios. El Estado argentino se constituye por veintitrés provincias y una Ciudad Autónoma (Ciudad de Buenos Aires) con una extensión territorial de $3.761 .274 \mathrm{~km}^{22}$ y una población de 42.119 millones de habitantes

1. La descentralización política, es decir la reforma de los sistemas electorales o constitucionales que devuelve capacidades y autonomía electorales o políticas a los niveles y actores políticos subnacionales emerge en el marco neoliberalismo en la década de los noventas. La ultima reforma constitucional de la Republica Argentina data del año 1994, durante la primera presidencia de Carlos Menen.

2. De los cuales: $2.791 .810 \mathrm{~km}^{2}$ corresponden al Continente Americano; $969.464 \mathrm{~km}^{2}$ corresponden al Continente Antártico (incluyendo las islas Orcadas del Sur) y a las islas australes (Georgias del Sur y Sandwich del Sur). Datos extraídos del Instituto Geografico Nacional de la Républica Argentina: http://www. ign.gob.ar/NuestrasActividades/Geografia/DatosArgentina/LimitesSuperficiesyPuntosExtremos 
(INDEC, 2010) que se concentran principalmente en la provincia de Buenos Aires (el 38,9\% de la población del país). En Argentina, se observa una importante disparidad en lo relativo a la distribución poblacional en Buenos Aires (macrocefalia), asimismo el modelo de concentración población en zonas urbanas se replica en las ciudades del interior del país ${ }^{3}$, en consecuencia, la densidad poblacional media es de $14,4 \mathrm{hab} / \mathrm{km}^{2}$.

Por ultimo, los municipios son los ámbitos de actuación gubernamental a nivel local. Existen 2.171 municipios y comunas en Argentina, y también se evidencia el mismo fenómeno de concentración de la población en las ciudades. Es decir, la mayoría de la población de los municipios se concentra en las cabeceras municipales siendo muy bajo el porcentaje de población rural. Sin embargo, los municipios pequeños representan el 80\% del universo y tienen una población promedio de 2.400 habitantes, en tanto los municipios grandes, apenas el $1 \%$ del total, pero concentran al 39\% de la población nacional (ITURBURU, 2000).

Lo que caracteriza al federalismo es el gobierno dividido verticalmente con poderes separados entre las instituciones centrales y las no centrales (COLOMER, 2001). En tal sentido, la división de funciones entre el gobierno central y subnacional es fundamental, debido a que algunas materias son exclusivas de los gobiernos subnacionales mientras otras de los gobiernos centrales (GIBSON, 2004; RIKER, 1996).

En materia de gestión de recursos naturales según la última parte del artículo 124 de la Constitución Nacional (1994) se menciona que: "corresponde a las provincias el dominio originario de los recursos naturales existentes en su territorio".

Desde la perspectiva organizacional del federalismo, la eficacia y eficiencia de la organización jurídico-política del país depende de consensos permanentes sobre los lineamientos generales de las políticas de estado en todos los órdenes: político, económico, social, cultural, etc. Así, el federalismo se trata de una forma de organización institucional que procura la descentralización política y administrativa del gobierno, y para ello, es necesario que el sistema político se funde en la concertación, en el dialogo y la coordinación intergubernamental permanente. En tal sentido, la política minera requiere de la coordinación entre las provincias y el Estado Nación a partir de Acuerdos Federales Mineros 4 .

En los países federales lo que forja el carácter de las relaciones entre los diferentes niveles de gobierno es la disputa por la apropiación de los recursos y la definición de las reglas que regulan la distribución de la renta los mismos (TOMMASI et al., 2001;

3. En Argentina, de la gran mayoría de habitantes (36.517.332 de los 42.119 millones de habitantes) reside en areas urbanas. INDEC. Censo Nacional de Población, Hogares y Viviendas 2010.

4. En Argentina el primer Acuerdo Federal Minero se realizó en el año 1993 con la intención de armonizar los aspectos fiscales y que las provincias adhieran a la Ley de inversiones mineras, luego en el 2012 se genera la OFEMI como un espacio de coordinación política entre Nación y las provincias, por ultimo, durante el gobierno de Macri se convoca a un nuevo Acuerdo Federal Minero (2017) a fin de fomentar las inversiones mineras. 
MONTERO, 2004; GORDIN, 2006; DÍAZCAYEROS, 2005 y 2006), siendo los actores principales de estas negociaciones el Poder Ejecutivo Federal y los gobernadores provinciales (OLMEDA, 2012). No obstante, lo paradójico es que, en el debate intergubernamental se diluye el aspecto territorial intrínseco que conlleva la localización de los recursos mineros en espacios específicos, y en tal sentido, se relativiza la participación en el diseño de la política minera de los intereses de los municipios.

Por su parte, la República de Ecuador es un Estado unitario que se gobierna de manera descentralizada. Ecuador se divide administrativamente en veinticuatro provincias y doscientos veintiún municipios o gobiernos autónomos descentralizados (GAD's). El país se define como plurinacional y presenta una superficie de 283.561 $\mathrm{km}^{2}$ con una población de 14.483.499 habitantes (INEC, 2010). El 63\% de los habitantes se localiza en áreas urbanas, principalmente en Quito y Guayaquil (bicefalia urbana). Al tratarse de un país de menor extensión territorial la densidad poblacional media es de $51 \mathrm{hab} / \mathrm{km}^{2}$, en tal sentido se puede asumir que el impacto de las actividades extractivas tiene una mayor incidencia en las comunidades, incrementando el nivel de conflictividad social.
En Ecuador la política minera la coordina el Estado Nacional y la minería es considerada como un sector estratégico, para lo cual en agosto de 2016 se realizo un Plan Nacional de Desarrollo del sector minero.

Cabe destacar que, si bien Argentina y Ecuador tienen formas de estado diferentes, ambos países presentan regímenes democráticos con sistemas de gobierno presidencialista y, en ambos casos, se revelan rastros de una fuerte concentración de poder en la figura del presidente.

En términos macroeconómicos, Argentina presenta un producto bruto interno per cápita, a precios constantes de mercado de 10.254.1 dólares ${ }^{5}$ para el año 2016, mientras Ecuador registra un producto bruto interno per cápita, a precios constantes de 5.210.3 dólares ${ }^{6}$ para el mismo periodo, según los datos publicados por la CEPAL? . Mientras, en Argentina la participación de los productos primarios sobre el total de exportaciones es del 73,4\% ; en Ecuador la exportación de productos primarios representa el 92,5\% del total (CEPAL, 2017). En otras palabras, en la economía ecuatoriana la industria es muy insipiente, y su estructura productiva depende principalmente del petróleo, por ello, la abrupta caída de los precios del petróleo afectó severa y bruscamente al presupuesto estatal. En conse-

5. En dólares a precios constantes de 2010. CEPAL, calculado sobre la base de datos oficiales de los países, 2016. 6. En dólares a precios constantes de 2010. CEPAL, calculado sobre la base de datos oficiales de los países, 2016. 7. Anuario Estadístico de América Latina y el Caribe, CEPAL, 2017. Hacemos referencia a las concepciones más liberales de Estado que sostienen la no intervención del mismo en el mercado y los teóricos del libre mercado, los cuales consideran al mismo como una entidad separada autorregulada e independiente de la sociedad. 
cuencia, el gobierno ecuatoriano visualizó a la minería como una alternativa viable para compensar los desequilibrios fiscales.

Asimismo, entre 2014 y 2015, el mayor crecimiento de entrada de inversión extranjera directa se produjo en la Argentina con un 130\%, mientras en Ecuador la inversión extranjera disminuyo aproximadamente en un 27\% (CEPAL, 2016), ello durante los últimos años del gobierno de Rafael Correa.

En la República Argentina, el 75\% de las áreas con potencial minero se encuentran aún sin explorar. Gran parte de los depósitos minerales se localizan en la Cordillera de Los Andes, a lo largo de sus 4.500 kilómetros de extensión, donde se pueden identificar los principales distritos mineros en exploración y explotación. En provincias como Catamarca, Salta, Jujuy, Mendoza, San Juan, Santa Cruz, Rio Negro y Neuquén.

Por su parte, en Ecuador la riqueza mineral no ha sido explotada y sólo el 10\% del área fue explorada. Los depósitos mineros se localizan en la estribación oriental de la Cordillera de Los Andes y los proyectos exploración considerados estratégicos se localizan en las provincias de Azuay (proyecto Loma Larga), Zamora Chinchipe (Fruto del Norte y Mirador) y Morona Santiago (Río Blanco y San Carlos de Panantza). Los cinco proyectos, más el proyecto Llurimagua, ubicado en Imbabura, deberían atraer inversiones aproximadas a los USD 8000 millones hasta 2024 (REA, 2017) históricamente, en las provincias de Manabí y Esmeraldas en la Costa; Azuay y Cañar en la Sierra, fueron las que más desarrollaron la minería. En las décadas de los 80s y 90s la Misión Británica realizó trabajos de investigación geológica en las cordilleras Oriental (REAL, 2017). A continuación, se observa un mapa con la localización de las principales provincias mineras de Ecuador y Argentina.

Ilustración 1 Localización de Argentina y Ecuador, y sus principales yacimientos mineros en explotación a gran escala

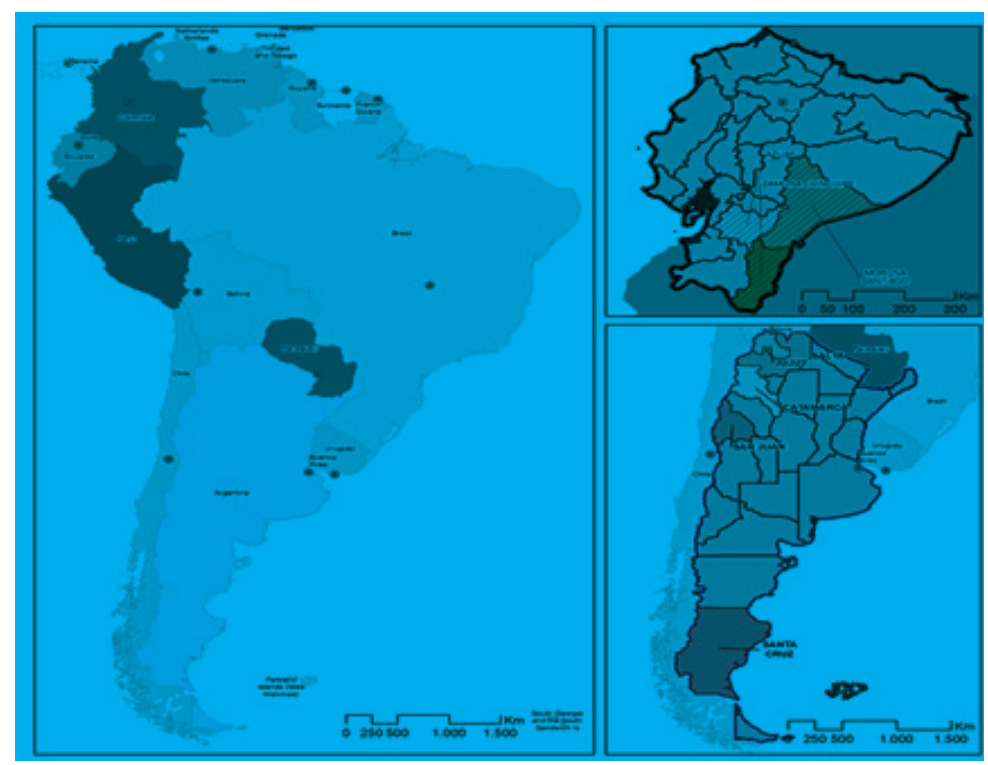

Fuente: Elaboración Propia. 


\section{El Estado y la multiescalaridad de la explotación minera a gran escala como modelo de inserción internacional}

La reformulación de escalas en los diversos procesos de globalización desplaza la visión estadocéntrica propia del Estado Moderno, en tal sentido, una dimensión que caracteriza a los conflictos socio ambientales es la multiescalaridad de los procesos, es decir se trata de un entramado complejo de actores sociales, económicos y políticos, locales, regionales, estatales y globales que se encuentran en interrelación. Así, cuando las luchas locales se dan contra ciertos actores globales, ya sea a escala global o en múltiples localidades, sus iniciativas locales pueden integrarse en una red global de activismo sin perder el foco sobre las causas específicas de su lugar (SASSEN, 2010).

En términos de Haesbaert (2011) bajo el proceso de glocalización, las localidades sufren la interferencia de lo global, es decir, las mismas se enfrentan a una combinación de elementos a partir del cual emerge una nueva dinámica donde estos componentes no pueden ser reconocidos estrictamente como globales, ni locales, pero sí como una amalgama cualitativamente distinta: global y local combinados al mismo tiempo como un nuevo proceso (HAESBAERT, 2011, p. 127).

Para el caso de las industrias extractivas, la dinámica entre "lo global" y "lo local" se presenta como un proceso en el que se cristalizan, por un lado, alianzas entre empresas transnacionales y Estados (en sus diferentes niveles), que promueven un determinado modelo de desarrollo y, por otro lado, resistencias provenientes de las comunidades locales, que cuestionan tal modelo, y reclaman su derecho a decidir en función de otras valoraciones. En este marco, los conflictos socioambientales a raíz de las economías de enclave tienden a encapsularse en la dimensión local. Dicha localización del conflicto se traduce por un deterioro mayor de los derechos civiles, a partir de los cuales éstos quedan librados a la intervención de la justicia y los entes municipales y/o provinciales, cuyo grado de vulnerabilidad frente a los actores globales es mayor que el de sus homólogos nacionales (SVAMPA, 2013b).

El territorio, la autoridad y los derechos no son simples atributos sino institucionalizaciones complejas que se atribuyen mediante procesos específicos y surgen de luchas e intereses conflictivos. Sin embargo, actualmente determinados elementos del territorio, la autoridad y los derechos se están reensamblando en configuraciones globales novedosas, en otras palabras, se están desnacionalizando (SASSEN, 2010).

Además, David Harvey (2003) argumenta que la relación dialéctica entre lógica política y la capitalista se evidencia a través de la formación de condiciones geográficas específicas. Es decir, las relaciones de intercambio desiguales respecto de aspectos claves como los recursos naturales, surgen por un lado, de la lógica capitalista, y por otro, son regulados mediante una lógica política (HARVEY, 2003).

Cabe destacar que si bien, la economía y la política suelen considerarse esferas relativamente separadas ${ }^{8}$, las relaciones entre

8. Hacemos referencia a las concepciones más liberales de Estado que sostienen la no intervención del mismo en el mercado y los teóricos del libre mercado, los cuales consideran al mismo como una entidad separada autorre-gulada e independiente de la sociedad. 
estos dos niveles se determinan, entre otras cosas, a partir del papel del Estado. Así, al comprender al Estado como una relación social, las correlaciones de fuerzas políticas que conforman el poder estatal juegan un papel central en la configuración del Estado de cada sociedad.

No se pretende aquí definir al Estado en términos de sus características institucionales formales y/o de los instrumentos fundacionales del poder del Estado. Sino más bien, se propone interpretar que el Estado y el sistema político pertenecen a un conjunto más amplio de las relaciones sociales. Es decir, el Estado cambia de forma y de apariencia en función de las actividades que desarrolla, de las escalas en las cuales opera, de las fuerzas políticas que actúan hacia él, de las circunstancias en las cuales aquellos y este último actúan (JESSOP, 2014, p. 12).

En otras palabras, en el presente artículo consideramos que es necesario partir del estudio crítico del Estado, entendiendo al mismo como un conjunto de instituciones, organizaciones y prácticas que están insertos socialmente e interrelacionados con otros órdenes institucionales y prácticas sociales (JESSOP, 2007).

Así, el Estado no es un sujeto/agente ni una herramienta neutral, "sino una relación social entre individuos y grupos sociales, que ésta mediada por su relación con las formas institucionales de gobierno y constituida a través de personas jurídicas y ciudadanos de una nación" (DEMIROVIC; HIRSCH; JESSOP, 2002, p. 19).

Por su parte, desde una perspectiva institucional Block y Evans (2007) también sostienen que "el Estado y la economía deberían verse como esferas de actividad que se constituyen mutuamente, y ninguna de las cuales puede funcionar sin la otra" (BLOCK; EVANS 2007, p. 308). Una de las caras de esta dependencia recíproca, radica en que los Estados necesitan de la economía para obtener los flujos de ingresos necesarios para financiar sus actividades (TILLY, 1991), y por consiguiente el modo en cómo se establezca esta relación, también va a determinar los márgenes de autonomía de cada gobierno.

En suma, la relación entre la esfera política y la económica se hace visible también a través de la autonomía relativa del Estado. Esto manifiesta cuánta autonomía tienen las correlaciones de las fuerzas políticas frente a las estructuras de clase. Además, la relación entre estas dos esferas también se transparenta en los distintos niveles espaciales interrelacionados (RADHUBER, 2014, p. 81).

Más aún, las dos funciones básicas $\mathrm{y}$ conflictivas del Estado se desprenden de las tensiones entre las necesidades económicas y las demandas políticas, y ello también se relaciona con las funciones de legitimación y acumulación (OFFE, 1977; LESSENICH; BORCHERT, 2005; HABERMAS, 1973; O'CONNOR, 1974). Así, el Estado debe contribuir de forma activa o pasiva en el proceso de acumulación, ya que las condiciones para la acumulación rentable aseguran también sus propios ingresos. Sin embargo, las funciones de acumulación y legitimación son contradictorias, ya que la aplicación de la fuerza para garantizar las condiciones de acumulación, amenaza la legitimidad por parte de los ciudadanos (RADHUBER, 2014, p. 72).

En consecuencia, la expresión real del poder del Estado dependerá del cambiante equilibrio de fuerzas sociales involucradas en la acción política, tanto dentro como fuera del Estado, la cual no se reducen sólo a la noción de clase, sino a diversas correlaciones de fuerza como: género, grupo étnico, de fuerzas políticas, relaciones con la natu- 
raleza y movimientos sociales en la sociedad civil. De este modo, el Estado es una relación social en función de la cual las relaciones de poder son condensadas y materializadas precisamente a través del conjunto de instituciones y centros de poder que lo constituyen (JESSOP, 2007, p. 46; Espinoza, 2014).

Dicho lo anterior, la internacionalización de los Estados nacionales a raíz de la globalización, suscitó que los países en desarrollo se volvieron parte de un mercado mundial en veloz integración al abrir sus sectores económicos, y reglamentados por normas globales y administrados por instituciones de gobierno económico tales como la Organización Mundial del Comercio, el Fondo Monetario Internacional y el Banco Mundial (EVANS; SEWELL, 2013). En tal contexto, para muchos países del Sur, la integración de sus economías al libre mercado global significó una mayor dependencia de la naturaleza y una erosión de los proyectos estatales de desarrollo nacional. De este modo, la naturaleza se convirtió en la ventaja comparativa más segura para las naciones periféricas (CORONIL, 2003).

Eduardo Galeano (1971) en su obra "las venas abiertas de América Latina", ya exponía como los sectores empresariales extranjeros debilitaban al Estado en la región. Sin embargo, el debate del neoextractivismo ${ }^{9}$ como modelo de desarrollo se ha consolidado en las últimas décadas, a través de la mirada crítica de diversos autores y colectivos de investigación de la región (SVAMPA, 2010; GUDYNAS, 2009; MACHADO ARAOZ, 2014; BEBBINGTON, 2007; ACOSTA, 2009).

La consolidación de este modelo de desarrollo en la región impulsó la expansión de la frontera productiva del territorio nacional hacia territorios antes considerados como improductivos y/o vacios, desde la lógica de producción capitalista.

Como menciona el geógrafo brasilero Milton Santos (2006) la expansión de las fronteras extractivas genera una contradicción entre la razón global y la local y, al resurgir el interés extractivo por los recursos naturales o los bienes comunes, se produce un desplazamiento en los mecanismos de regulación política que modifica radicalmente las relaciones entre espacio y poder estatal (CIUFFOLINI, 2012). Esta modificación radica en la disipación de la ilusión de competencia y control sobre el territorio por parte del Estado, en favor de una amplia autonomía del capital que se expresa en la diversidad de tecnologías que requiere para hacer posible la explotación de los recursos, los cuerpos y los tiempos de trabajo (FOUCAULT, 2006; CIUFFOLINI, 2012). En otras palabras, el resultado de este proceso es que se está constituyendo un espacio global para la acumula-

9. Se entiende por "extractivismo", al régimen de acumulación capitalista, cuyo modelo de abundancia se basa en un patrón de acumulación caracterizado por la sobreexplotación de recursos naturales no renovables y cada vez más escasos. La explotación de estos recursos se extiende a territorios que hasta ahora se consideraban improductivos, y comprende las actividades de sectores tradicionales como minería e hidrocarburos, como asimismo otras actividades tales como la silvicultura, la agroindustria o la producción de agro combustibles (SVAMPA, 2013a) 
ción del capital (ROBINSON, 2013).

El términos de acumulación se entiende en un doble sentido, por un lado la acumulación como extracción y apropiación de excedentes del trabajo de los pueblos en los procesos de aprovechamiento de los recursos naturales de sus territorios, por el otro, de intensa acumulación de capital fijo en el marco de procesos de ajuste espacial en porciones del territorio, ajuntando y remodelando el espacio mediante la construcción de infraestructura, equipamientos y políticas publicas territoriales, a efectos de proveer las condiciones de producción para el despliegue y realización de los procesos de extracción y apropiación de excedentes en las comunidades (SCHWEITZER, 2016, p. 140).

El despliegue de estos fenómenos no ocurre en iguales magnitudes en el conjunto del espacio geográfico. De hecho, los procesos de diferenciación, en el marco de la fijación de capitales en el espacio, constituyen uno de los principales motores de las dinámicas del desarrollo geográfico desigual y combinado (Schweitzer, 2013, p. 54).

A raíz de la racionalidad económica del capital autonomizado y global, se observa cómo se pone a competir a las necesidades macroeconómicas del Gobierno Nacional con el dinamismo socioeconómico de la propia lógica local, ello principalmente por las prometedoras inversiones vinculadas a la extracción de los recursos no renovables que se localizan en territorios alejados de los centros de poder y económicos de los países.

\section{La trayectoria de las políticas mineras en Argentina y Ecuador}

Desde inicios de los noventa hasta la actualidad, el Estado ejerce una práctica discursiva que legitima a la minería como una actividad dinamizadora del desarrollo local y promotora de empleo. Lo paradójico es que desde la lógica neoliberal o del desarrollismo más progresista, se deja de lado la especificidad de lo local y las representaciones de los propios actores. Por ello, diversos autores de la Geografía Crítica $^{10}$ (Harvey, Santos, Soja, Godelier, entre otros) sostienen que el espacio se encuentra “(...) completamente atravesado y constituido por las relaciones social-históricas, o, de modo más estricto, relaciones de poder" (HAESBAERT, 2011).

Así, las áreas definidas como "sacrificables” por parte de las políticas públicas

10. La escuela de la geografía crítica se interesa por el espacio producido por las relaciones sociales y por la relación entre sociedad y naturaleza, considerándolo como un producto eminentemente social. Por ello, el espacio debe estudiarse como una totalidad estructural, esencialmente histórica, política, relacional y contradictoria que participa tanto de lo social como de lo natural (SANTOS, 2000); como un producto social y económico, y no como un puro soporte físico (SEGRELLES, 2000); como un producto social dinámico cuyo factor de dinamicidad y transformación esencial es el modo de producción capitalista (HARVEY, 2007; SMITH, 2008). Mientras, la territorialidad se comprende como una relación entre sujetos sociales en la que el poder ejercido sobre el espacio constituye el elemento mediador, los sujetos sociales apropian dicho territorio o ejercen el poder sobre el mismo en función del control de las actividades económicas, sociales y políticas para la realización de sus intencionalidades (RAFFESTIN, 2011). 
de desarrollo son aquellas que hasta hace poco habían estado marginalizadas por los diferentes periodos de reproducción capitalista. Se establece una relación dialéctica entre aquellos espacios de sacrificio y los que obtienen beneficios. En otras palabras, el poder define, a través de la planificación nacional, los espacios, territorios y pueblos que necesitan ser descartados en pos del bien nacional (SILVEIRA et al., 2016).

En Argentina, la política minera a nivel nacional se podría dividir en cuatro periodos temporales principales. Una primera etapa, desde fines de los 40' hasta los 70', en la cual la minería era destinada al mercado interno y se producía principalmente rocas de aplicación y la extracción de minerales metalíferos estaba orientada a la producción industrial nacional. Los recursos mineros eran considerados como estratégicos y eran controlados por el Estado a través de la Dirección General de Fabricaciones Militares.

En segundo lugar, con el advenimiento de la globalización y el neoliberalismo en la década de los noventa, la Reforma del Estado en un contexto de desequilibrios económico fomenta el ingreso de la República Argentina al negocio mega minero internacional con un marco legal muy ventajoso al capital transnacional, que permitió la instalación de Minera Alumbrera Ltda. (Glencore, Goldcorp y Yamana Inc), Minera del Altiplano FMC (FMC Corporation) y de Minera Cerro Vanguardia (Anglo Gold Ashanti).

En un tercer momento, durante el kirchnerismo persiste una manifiesta continuidad en el apoyo y promoción del crecimiento de la minería; en tal sentido se evidencia una ola creciente de inversiones en el sector extractivo en Argentina entre 2002 y 2011. Así, la inversión en minería aumentó en un $1,948 \%$, de $\$ 541$ millones a $\$ 11.078$ millones de pesos, y la producción del sector expandió en un 841\%, de 3.365 millones de toneladas a $31.652 \mathrm{mi}$ llones de toneladas. Asimismo, el número de proyectos mineros de incrementó en un 3.311\%, de 18 a 6147 (SAGUIER; PEINAD0, 2015). Este aumento significativo de inversiones trajo aparejado el florecimiento de numerosos conflictos socioambientales con la contra respuesta del Estado Nacional de impulsar una organización de coordinación federal en materia minera, como lo es la Organización Federal de Estados Mineros (OFEMI).

Por último, con el giro ideológico del gobierno de Macri, se ha generado un fortalecimiento del sector minero y como estrategia de coordinación se realizó el segundo Acuerdo Federal Minero entre las provincias y la Nación (cuarta etapa).

Por su parte en Ecuador, la minería artesanal es parte del acervo cultural desde los orígenes mismos del Estado y es una manera de subsistencia de muchas familias aún en la actualidad. Sin embargo, la minería a gran escala es una actividad aún incipiente en el país. Los primeros trabajos en exploración en minería datan de 1960 con el arribo al país de una misión británica, financiada por las Naciones Unidas, a fin de elaborar el mapa geológico. A su vez, no se evidencia un plan sistemático de exploración de los recursos minerales por parte del Estado nacional, sino a partir del año 2008. Además, a diferencia de Argentina, en la trayectoria minera del país no hubo una conexión entre la explotación minera como un eslabón de la industrialización nacional, principalmente porque el ciclo productivo que ha movilizado la economía ecuatoriana desde los años setenta ha sido la explotación petrolera. En consecuencia, 
las riquezas minerales han sido consideradas como un resguardo del patrimonio nacional ecuatoriano y, recién a partir del año 2008 se comienza a incentivar la actividad como una política de estado, a raíz de la reforma constitucional del Ecuador y la promulgación de la minería como uno de los sectores estratégicos, para dar impulso al desarrollo nacional.

Además, cabe destacar que en la última reforma Constitucional de Ecuador se establece una nueva forma de convivencia ciudadana en diversidad y armonía con la naturaleza con la finalidad de alcanzar el buen vivir "Sumak Kawsay". Por ello, el Gobierno debe garantizar los derechos de las personas, las colectividades y la naturaleza en igualdad de condiciones. En estos términos, se trata de un marco legal novedoso, pero aún los efectos de la instrumentalización de la política minera en el país son inciertos.

El 18 de abril de 2008, la Asamblea Constituyente ecuatoriana de plenos poderes expidió el Mandato Minero con la finalidad de corregir las principales dificultades que se visualizaban en el manejo de las reservas minerales. Asimismo, dicho Mandato Minero estableció la creación de una empresa minera del Estado como pieza central de intervención y gestión en este sector. De este modo, la empresa actuaría en la regulación de la actividad minera, estableciendo las condiciones necesarias para que el Estado invierta en tecnología y determine otras reglas que organicen el sector, sin depender de los capitales de empresas extranjeras. Además, la entidad proveería de financiamiento a los pequeños mineros y a los mineros artesanales y, sobre todo, mejoraría el manejo social y ambiental de la actividad. En cumplimiento con el Mandato Minero, la ENAMI (Empresa Nacional
Minera) fue creada el 31 de diciembre de 2009. No obstante, una de las principales críticas desde el sector académico es el convenio que se firmó con la empresa estatal chilena Codelco, la cual debe mediar entre su papel de asesora del Estado ecuatoriano y su interés particular en la generación de negocios con las empresas chinas en el mismo rubro, lo cual podría generar un conflicto de intereses.

Menos de un año después del Mandato Minero se establece la Ley General Minera (Registro Oficial No. 517, 29 de enero del 2009). Se trata de la normativa principal en materia de regulación de la actividad minera.

La nueva ley minera es superadora al marco legal imperante en los noventa en la era neoliberal. En este caso, se observa un retorno del Estado como ente regulador del sector minero. Además de la creación de una Empresa Nacional Minera, se establece la necesidad de que los Estudios de Impacto Ambiental sean revisados por el Ministerio del Ambiente, y para ello la empresa debe obtener una licencia ambiental emitida por el Ministerio del Ambiente —el mismo caso en la extracción petrolera- . Además, las empresas mineras deberán presentar anualmente una auditoría ambiental (Art. 78), mientras que sus concesiones mineras puedan ser revocadas por impactos sociales, culturales y ambientales. En el ámbito tributario, la ley restaura el pago por concepto de regalías, las cuales no deben ser menores al 5\% de las ventas del mineral y de los ingresos obtenidos el 60\% de regalías serán destinadas a proyectos de desarrollo local a través de los gobiernos municipales. Además, la ley establece también un pago correspondiente al 25\% del impuesto a la renta, el 12\% de las utilidades y el 12\% del impuesto al valor agregado. Igualmente se 
considera un pago del 70\% como impuesto a los ingresos extraordinarios. Cómo falencias en la implementación de la legislación se menciona la permisividad en materia de manejo de títulos mineros y de régimen fiscal, su preeminencia sobre otras leyes, sus debilidades en el ámbito socio-ambiental, la poca apertura a la participación de las comunidades afectadas (LATORRE; SANTILLANA, 2009; ACOSTA; 2009).

Por su parte, en Argentina el marco legal minero imperante data de inicios de los años noventa y el mismo emerge bajo un contexto de hiperinflación, recesión, deuda externa, caída de las reservas y fuga de capitales, por ello las prometedoras inversiones externas en minería se asumían como un alivio para las desequilibradas cuestas nacionales. Además, a escala global se acentuaba el proceso de globalización capitalista, el cual supuso un cambio significativo en el proceso productivo mundial que pone a competir a los distintos espacios territoriales nacionales $-\mathrm{y}$ subnacionalespara capturar porciones cada vez más volátiles del capital global y anclarlas de manera productiva dentro de sus fronteras (THWAITES REY, 2010).

Un hito fundamental para la política minera Argentina, es la reforma de la Constitución Nacional de 1994 debido a que se establece explícitamente que le "corresponde a las provincias el dominio originario de los recursos naturales existentes en su territorio". Con ello se generó un marco legal sin precedentes en la región en la relación Estado-mercado (multinacionales mineras). De modo que, el Estado Nación pierde injerencia de contralor sobre los minerales ya que, según lo establece el artículo 124 de la Constitución Nacional, son las provincias las auditoras del cumplimiento de la ley al considerarse que son las propietarias origi- narias del subsuelo. Ello tiende a debilitar el poder de disciplinamiento por parte del Estado sobre el capital internacional que opera en el sector minero.

En Argentina, el acuerdo legal favorable que le dio impulso a la actividad minera a gran escala se plasma en el Código de Minería - reglamentado mediante decreto 456/97- y en numerosas reformas que se originaron en varios cuerpos legales dictados a partir del año 1993. Pueden registrarse, entre otras, a la ley de Inversiones Mineras No. 24.196; de Reordenamiento Minero No. 24.224; de Actualización Minera No. 24.498; de Protección Ambiental en Materia Minera No. 24.585.

Sin embargo, la Ley 24.196 de Inversiones Mineras es una de las más significativas porque en la misma, se establece que los emprendimientos mineros gozarán de estabilidad fiscal por el término de treinta años - a partir de la fecha de presentación del estudio de factibilidad - además, se estipula que el monto máximo que las provincias pueden percibir en concepto de regalías mineras es del 3\% del valor de boca de mina. Aunque el monto que efectivamente pagan las empresas es de $1,2 \%$ a $1,5 \%$ porque se toma el valor de boca de mina y se le deben deducir una serie de gastos del proyecto (GAMBINA; LIZUAIN; PAPI, 2010, p. 416).

Se debe agregar que en Argentina el proceso de concesión legal minera se realiza por registro de descubrimiento (manifestación del hallazgo con la muestra de mineral y un plan de inversión) a diferencia de Ecuador donde las concesiones se realizan a través de una convocatoria, a cargo del Estado, en donde se presentan los oferentes para una subasta o remate con sus respectivos planes de inversión en sobre cerrado.

A raíz de la racionalidad económica del capital autonomizado y global, se observa 
cómo se pone a competir a las necesidades macroeconómicas del Gobierno Nacional con el dinamismo socioeconómico de la propia lógica local, ello principalmente por las prometedoras inversiones vinculadas a la extracción de los recursos no renovables que se localizan en territorios alejados de los centros de poder y económicos del país. Por su parte, las provincias mineras, con relación a los centros económicos más dinámicos del país, poseen un desarrollo productivo industrial tardío, consideran a la minería como una fuente de ingresos necesaria para equilibrar las debilitadas cuentas fiscales. Por último, los territorios donde se sitúan los yacimientos en explotación representan el eslabón más débil de la política minera, y personifican a las necesidades de las comunidades rurales y pobres que asumen los costes de un sistema de producción de riqueza que los excluye.

En Argentina se registran 29 conflictos socioambientales por la explotación minera a lo largo de la Cordillera de Los Andes, mientras en Ecuador (aún sin encontrarse en fase de producción a gran escala) presenta en la actualidad siete conflictos entre comunidades y las empresas mineras, según el relevamiento del Observatorio de Conflictos Mineros de Latinoamérica ${ }^{11}$. Las disputas emergen como una manifestación de resistencia ante relaciones sociales desiguales, excluyentes y no democráticas que se presentan en los escenarios locales como por ejemplo: las asambleas de auto convocados en Andalgalá, Santa María, Belén y Tinogasta (Catamarca) y Amaicha del Valle (Tucumán) o el levantamiento social en contra de la minería a cielo abierto en Famatina (La Rioja), el plebiscito de Esquel (Chubut), o la resistencia a la aplicación a la Ley de Glaciares de algunos gobiernos provinciales como San Juan o Catamarca.

Asimismo, se puede hacer referencia a los reiterados derrames de agua cianurada durante el proceso de extracción de oro y plata en la mina Veladero en el transcurso del año 2015 y 2016, a cargo de la empresa Barrick Gold, que provocó la contaminación de cinco ríos en la provincia cordillerana de San Juan. También podemos mencionar, el reciente procesamiento del gerente general de Minera Alumbrera por violación a la ley de residuos peligrosos que generó la contaminación de la cuenca del río Salí-Dulce ${ }^{12}$. Estos hechos se suman a unas 1.500 causas medioambientales judicializadas en la Unidad Fiscal para la Investigación de Delitos Contra el Medio Ambiente, creada en el año 2006 bajo la órbita de la Procuración General de la Nación.

En consecuencia, en los últimos doce años se multiplicaron las resistencias al modelo de desarrollo extractivista y emergieron los denominados "Nuevos Movimientos Sociales”. Diversas corrientes teó-

11. Mapa de conflictos mineros. https://mapa.conflictosmineros.net/ocmal db-v2/conflicto/lista/02031300 ultima visita, 17 de abril de 2018.

12. Cabe destacar que dicha causa judicial se inició hace 16 años y que Minera Alumbrera anunció el cierre de sus operaciones para el 2017. 
ricas analizaron ampliamente estos sujetos colectivos con énfasis en algunos aspectos específicos que los distinguen de los actores tradicionales para la canalización de las demandas sociales, como pueden ser los sindicatos y partidos políticos. Sin embargo, poco se indaga en la presencia de la institucionalidad estatal como un actor de relevancia en las tensiones socioambientales resientes. Como bien lo menciona Ciuffolini y de la Vega (2011), las disposiciones estatales colaboran en gran medida a crear instituciones y relaciones sociales que, regulando cuestiones ambientales y relativas a recursos naturales, materializan situaciones de dominación. Es decir, si las luchas ambientales han venido a denunciar ciertas condiciones consideradas injustas, sometidas pero también rechazadas por sistemas institucionales y jurídicos estatales, se hace necesaria una mirada sobre las decisiones e intervenciones del Estado (CIUFFOLINI; DE LA VEGA 2012). En síntesis, se evidencian relaciones contradictorias entre capitales y sus lógicas y las condiciones de producción y reproducción de las poblaciones.

Luego, si bien en el propósito del trabajo no prima el análisis del manejo ambiental, por la relevancia política del hecho cabe recordar el veto del Poder Ejecutivo Nacional ${ }^{13}$ a la Ley de presupuestos mínimos para la protección de los glaciares y del ambiente, previamente aprobada por el congreso nacional en noviembre de 2008. De ahí que, tras el veto presidencial, legisladores oficialistas (FPV) promovieron una nueva ley de presupuestos mínimos para la protección de glaciares más flexible, que se aprobó en el Senado de la Nación en octubre del 2009, la cual satisfacía las condiciones de aprobación de proyectos mineros como Pascua Lama. No obstante, en agosto de 2010 se introdujeron modificaciones a dicha ley ${ }^{14}$ por parte de la oposición, buscando que la nueva normativa ambiental amplié el concepto de área periglaciar a conservar, entre otros ajustes (PRADO, 2005). Sin embargo, la Ley de Glaciares hasta la fecha se encuentra flagrantemente incumplida.

La potestad de los recursos mineros, en el caso de Ecuador, es de propiedad inalienable, imprescriptible e inembargable del Estado. La minería es un sector estratégico, sobre los cuales el Estado se reserva el derecho de administrar, regular, controlar y gestionar. Aunque puede delegar de manera excepcional a la iniciativa privada de acuerdo con el Plan Nacional de Desarrollo.

Cabe destacar que aún ninguno de los cinco proyectos mineros considerados estratégicos por la Secretaría Nacional de Planificación y Desarrollo (SENPLADES), se encuentra en etapa de explotación, no obstante, la fase de exploración ha suscitado

13. El Decreto 1837/08 argumentaba que el establecimiento de presupuestos mínimos no debería prohibir las actividades productivas de manera absoluta porque ello podía afectar el desarrollo económico de las provincias afectadas.

14. Ley Nacional 26.639 de Presupuestos Mínimos - Ley de Protección de Glaciares y Ambiente Periglaciar. 
varios conflictos socioambientales, como, por ejemplo, el caso que busca desarrollar el megaproyecto minero Loma Larga, que genera la resistencia de la localidad de Quimsacocha. También, se pueden nombrar las resistencias de las comunidades del Intag que expusieron estar en contra del proyecto minero Llurimagua a cargo de la empresa estatal Enami EP y la compañía chilena Codelco, para la explotación de cobre y molibdeno, porque vulnera derechos de territorios indígenas. Por su parte, el proyecto El Mirador (Zamora Chinchipe), operada por Ecuacorriente (ECSA), subsidiaria ecuatoriana del consorcio chino CRCC-Tongguan tuvo retrasos en el avance del proyecto debido a graves denuncias sobre incumplimientos ambientales ${ }^{15}$, vulneración de derechos laborales y cuestionamientos a los procesos de consulta previa.

Las comunidades se quejan de que los procesos de información de las empresas extractivas son escasos e incompletos. $\mathrm{Mu}-$ chas veces, sostienen, no son realizados. Las empresas, por su parte, dicen que las consultas terminan siendo cooptadas por personas que se oponen al progreso y buscan dilatar los proyectos (PAZ, 2019).

Por ultimo, es importante resaltar que en febrero del 2018 se realizo una consulta popular a nivel nacional, en donde se puso sobre el tapete dos temas de gran importancia para la gestión ambiental como la limitación de la minería metálica y la protección del Parque Nacional Yasuní. Por una parte, la población si estaba de acuerdo con enmendar la Constitución de la República del Ecuador para que se prohibiera la minería metálica en todas sus etapas, en áreas protegidas, en zonas intangibles, y centros urbanos (68,62\%). Además, se les pregunto a los ciudadanos si estaban de acuerdo con incrementar la zona intangible en el Parque Nacional Yasuní al menos en 50 mil hectáreas y reducir el área de explotación petrolera autorizada por la Asamblea Nacional de 1030 hectáreas a 300 hectáreas. El sí obtuvo un 67,31\% de los votos. Sin embargo, los líderes sociales y ambientalistas ponen en duda el efectivo cumplimiento y argumentan que sería ingenuo pensar que el Estado vaya en contra de los intereses del capital.

En Argentina, los estados provinciales tienen el dominio originario de los recursos naturales, sin embargo, el Estado no puede explotar ni disponer de las minas, por ello concede a los particulares la facultad de disponer de ellas como dueños. Por ello, cada provincia argentina cuenta con una

15. El Ministerio de Ambiente de Ecuador indico que el Proyecto Minero Mirador incumple con el Estudio de Impacto Ambiental (EIA) y Plan de Manejo Ambiental (PMA) aprobado, respecto a la apertura de vías $\mathrm{y}$ trabajos no contemplados en los mismos, por lo que se ha iniciado el respectivo proceso administrativo, sin perjuicio de remediar las áreas afectadas. Entre los principales incumplimientos se encuentran; el mal manejo de combustibles; falta de actividades de rehabilitación de las laderas y quebradas afectadas; plantación de especies herbáceas como gramalote para estabilizar el suelo; inadecuado tratamiento para la disposición final de los lodos de perforación en algunas plataformas; entre otras observaciones.

http://www.ambiente.gob.ec/ministerio-del-ambiente-dispone-suspension-de-actividades-por-afectacion-ambiental/, ultima visita 5 de abril de 2019. 
autoridad minera que se encarga de regular y realizar la concesión minera. A modo de ejemplo, Catamarca una de las principales provincias mineras del país, se basa en el Código de Procedimiento Minero que data del año 1967, por ende, no considera los cambios tecnológicos de la actividad y el proceso de concesión no cumple con los estándares mínimos de transparencia. Asimismo, en términos de control ambiental la Secretaría de Ambiente de la provincia puede realizar sugerencias sobre el cumplimiento del plan de manejo ambiental, sin embargo, los informes emitidos no son vinculantes. La competencia del control en materia minería depende de la Secretaría de Minería de la Provincia, a través de la policía minera. Lo paradójico es que la misma institución que debe promover las inversiones mineras tiene la potestad de control ambiental.

En cuanto al área de concesión se establece que en las provincias cuya extensión territorial exceda los $200.000 \mathrm{Km} 2$, el permiso podrá constar de hasta 40.000 Km2 (Ley 27.111), es decir se trata de enormes extensiones. En Ecuador, un país con una extensión de $283.560 \mathrm{Km} 2$, las empresas pueden solicitar concesiones de 500 a 5.000 hectáreas $(5 \mathrm{Km} 2$ a $50 \mathrm{Km} 2)$ para la gran minería y recientemente se realizó una consulta popular donde se prohíbe la extracción minera en áreas protegidas.

La autoridad de aplicación en Ecuador es el Ministerio de Minería de la Nación, quien regula el proceso de concesión minera. Los contratos de concesión son públicos y de libre acceso, es decir, el Geoportal del Ecuador proporciona acceso libre y gratuito al catastro minero. En otras palabras, se trata de un proceso más transparente que en Argentina, debido a que los contratos de concesión y el Banco Único de Registros Geológicos si bien deberían ser públicos no son de libre acceso.

\section{Regalías mineras comparadas}

En términos generales, el objetivo de las regalías es cobrar por la extracción de un recurso escaso, no renovable y valioso que se agota y que genera rentas extraordinarias. Por ello, en algunos países, el mineral de alta ley y mejor ubicado generan mayores rentas que otros de baja ley.

La regalía ${ }^{16}$ o royalty, es uno de los instrumentos más utilizados para grabar las actividades de extracción de recursos naturales (BAUNSGAARD, 2001). Las mismas, se pueden aplicar mediante dos mecanismos. El primero, es sobre el volumen de producción (ad quantum) y el segundo es sobre el valor bruto de la producción (ad valorem). Cuando se aplica una regalía sobre el volumen de producción pueden surgir problemas relacionados con sus costos de monitoreo. En particular si el recurso extraído no es homogéneo. Por otro lado,

16. Baunsgaard (2001) define la renta minera como la diferencia entre el precio de venta del commodites y el costo de oportunidad de proveer el recurso. Es interesante notar que este costo de oportunidad debe considerar la rentabilidad exigida por la inversión realizada; lo que debe cubrir los costos de exploración, extracción y producción, el costo del capital y el premio por riesgo. 
si la regalía se aplica sobre el valor de la producción se podrían generar problemas en la determinación del precio de venta del recurso si existen partes relacionadas en las transacciones. Tal es el caso de los precios de transferencia entre una casa matriz y sus filiales. Además, las regalías pueden ser cobradas sobre la base de costos brutos o netos. El último caso permite descontar los costos de producción y de transporte antes del cobro de la regalía.

Países como Bolivia, Brasil, Perú y Venezuela aplican las regalías sobre las ventas brutas. Mientras que Argentina aplica su regalía según el valor de boca de mina del recurso extraído. Es decir, el valor boca de mina es el valor obtenido en la primera etapa de su comercialización, menos los costos (directos e indirectos), según lo expuesto en la Ley Nacional de Inversiones Mineras en su artículo 22 bis.

Por otra parte, el marco legal nacional fijo que las provincias solo podían cobrar un 3\% (como tope máximo) en concepto de regalías mineras por la extracción de sus recursos naturales. De este modo, se instauró un criterio uniforme en todo el territorio nacional como estrategia de debilitamiento de la capacidad de negociación de los gobiernos provinciales, ya que previamente cada provincia establecía sus propios estándares en materia de regalías mineras y las empresas mineras lo veían como una amenaza a la seguridad jurídica y la rentabilidad.

Además, los modelos redistributivos de las regalías hacia los municipios son una facultad de cada gobierno provincial. Por ello, la distribución secundaria de las regalías se diferencia en cada provincia de la República Argentina. A saber:

- San Juan: La ley 7862 determina que el 70 por ciento de las regalías es para rentas generales de la provincia, el 10 por ciento para la Secretaría de Minería - para mejorar y reforzar los controles en los emprendimientos- y el 20 por ciento restante para la Municipalidad donde tenga su asiento el yacimiento minero.

- Santa cruz: Los ingresos en concepto de regalías mineras se dirigen en su totalidad a rentas generales de la provincia y representa el sistema más centralizado. Es decir, el sistema de distribución no les da participación directa a los municipios en las regalías, por ello, no se establece un tratamiento especial en cuanto al origen y destino de los fondos. Por su parte, la ley de coparticipación municipal determina que el Ejecutivo Provincial se atribuye el 93 por ciento de los recursos de las regalías petroleras, gasíferas y mineras y sólo se distribuye el 7 por ciento como fondos coparticipables entre los 14 municipios de la provincia patagónica.

- Salta: Es la provincia que más dinero redistribuye a los municipios. La provincia sancionó en 1986 la ley 6294 en la cual se establece que se asignará a los municipios un 20 por ciento de la recaudación por canon minero y canon de aprovechamiento y aguas. Asimismo, se redistribuyen las regalías mineras con una participación del 50 por ciento (del 3\%) de las mismas entre los municipios productores, por último, el 50 por ciento restante es para el Fondo Especial de Promoción Minera.

- Catamarca: Una de provincias mineras pioneras recién estableció la Ley 5128 de redistribución secundaria de las regalías hacia finales del año 2004, a pesar de que tanto Minera Alumbrera Ltda y Minera del Altiplano FMC comenzaron a 
exportar el mineral a partir del año 1997. Se trata del sistema redistributivo de las regalías mineras más complejo del país, porque que se realizó en base a un índice que les da participación a los 36 municipios de la provincia. Se asigna el 35 por ciento a los departamentos mineros: el 25 por ciento es para la comuna en donde está el yacimiento minero y el 10 por ciento restante para los municipios de la región. En caso de que el emprendimiento sea compartido por dos departamentos el monto se distribuye en partes iguales. Lo llamativo es que se distribuye considerando a los departamentos (16) y no a los municipios (36). Por su parte, el 65 por ciento de las regalías se destina al tesoro provincial, desde donde, además, se distribuye un 5 por ciento para el Fondo de Promoción y Desarrollo Minero y un 25 por ciento para los departamentos en los que no está el yacimiento, en base a las necesidades básicas insatisfechas.

En cuanto al criterio de destino de las regalías la legislación establece para el caso de Catamarca y San Juan limitaciones similares, es decir la ley ordena aplicarlas única y exclusivamente a financiar obras de infraestructura para el desarrollo económico y se prohíbe con ellas el pago de gastos corrientes.
Subyace así en el espíritu de la legislación la noción de que el "efecto distribuidor" permite una mayor aceptabilidad de la actividad minera y atenúa los conflictos sociales. Por consiguiente, la transferencia del poder de decisión política y económica sobre las regalías mineras a los gobiernos locales requiere un nuevo modelo de gestión que sea más participativo y que incorpore un enfoque territorial más integral. Además, es fundamental fortalecer a los municipios rurales en términos de capacidad institucional y política como capacidad técnica y administrativa para emprender planes de desarrollo económico local.

Por su parte, Ecuador en la actualidad se cobra regalías anticipadas, en otros términos, aplica un criterio de regalías basada en impuestos o ingresos. En la misma se aplica una tasa de porcentaje a una medida de beneficios contables realizada por el proyecto ${ }^{17}$. Luego, cuando el yacimiento minero se encuentre en producción, el cálculo de las regalías mineras se realizará en base a un porcentaje sobre la venta del mineral principal y de los minerales secundarios que la empresa presentará a través de declaración jurada al Servicio de Rentas Internas de manera semestral: marzo y septiembre de cada año.

En cuanto al monto en concepto de regalías que deberán pagar las empresas mineras concesionarias es no menor al 5\%

17. La base del beneficio contable se calcula a nivel del proyecto y puede que no sea consistente con la contribución que el proyecto hace a las ganancias consolidadas del titular sobre el cual se grava el impuesto al ingreso corporativo. Un impuesto basado en beneficios contables tiene mayor eficiencia en la distribución económica, pero resulta en ingresos gubernamentales inestables y altos costos de cumplimiento tanto para el gobierno como para la industria. Pietro Guj (2012), "Regalías mineras y otros impuestos específicos a la minería” International Mining for Development Centre (IM4DC), Universidad de Australia Occidental. 
de las ventas del mineral principal y de los minerales secundarios, mientras que, para el caso del oro, cobre y plata, el porcentaje no debe ser mayor al 8\%. Sin embargo, lo que el marco legal no aclara cuál es el criterio que subyace en la variabilidad para la asignación de los porcentajes a cobrar a las empresas, es decir: el monto que se les cobra a las empresas puede variar entre un 5\% al 8\%, siendo probable que cada empresa minera negocie condiciones distintas en materia de regalías dando lugar a tensiones y ambivalencias.

El criterio de redistribución de las regalías mineras establece que el $60 \%$ de la regalía (de ese 5\% al 8\%) se destinará al Gobierno Nacional o los Gobiernos autónomos descentralizados (GADs) para financiar proyectos de inversión social y desarrollo territorial o productivo. No obstante, la normativa no indica los porcentajes y los criterios redistributivos de ese 60\% de la regalía entre el Gobierno Nacional y los GADs, lo cual es una fuente latente de disputas políticas por mayores márgenes de captación de tales ingresos. Otra observación del marco legal es que en el mismo se deja un vacío o laguna legal en cuanto al otro $40 \%$ de las regalías, es decir, quien tiene la competencia de la administración (aunque se asume que es el Poder Ejecutivo Nacional). En cuanto al criterio para la asignación de las regalías, el Decreto Ejecutivo $\mathrm{N}^{\circ} 1135$ especifica que la asignación de recursos será "para proyectos de inversión social y desarrollo territorial en las áreas de influencia donde se ejecutan actividades de los sectores estratégicos”, aunque no queda claro qué se entiende por áreas de influen- cia de los proyectos mineros.

Se estima que el país andino recibió en concepto de regalías anticipadas $165 \mathrm{mi}-$ llones de dólares por parte de ECSA y Lunding Gold y con tales regalías el gobierno de Ecuador realizó obras de infraestructura básica como pavimentación, red de alcantarillado, etc. No hay una transferencia directa del dinero a los GADs municipales o comunidades para que administren estos fondos de acuerdo con las necesidades locales y con participación de los vecinos, sino es Ecuador Estratégico el que decide el destino de los fondos. Debido a que, es la mencionada institución nacional la que tiene la misión de ejecutar los planes de inversión para el desarrollo territorial en las áreas de influencia de los proyectos de los sectores estratégicos.

En Argentina como se menciono previamente las regalías son administradas por las provincias, mientras las retenciones a la exportación ${ }^{18}$ y los impuestos nacionales (impuesto a las ganancias, entre otros) son de recaudación nacional. A modo de ejemplo, Catamarca desde el año 2004 al 2013 percibió \$ 1.280.424.357,22 pesos (US\$ 196.083.362,51 según tipo de cambio oficial al 30 de diciembre del 2013) en concepto de regalías mineras y con las mismas se han realizado obras como un predio ferial, estadio de futbol, obras de infraestructura básica, entre otros. Sin embargo, Catamarca sigue siendo en la actualidad una de las provincias mas pobres del país, con poco dinamismo socioeconómico, siendo la principal fuente de empleo la administración publica. 


\section{Conclusiones}

Si bien Argentina y Ecuador presentan ciclos económicos diferentes, ambos países priorizan el pragmatismo económico como modelo de inserción internacional y estrategia de gobernabilidad ante la crisis económica que atraviesa la región, más que la sustentabilidad territorial y ambiental de las comunidades. Por ello, los gobiernos pierden legitimidad y se alejan de las estrategias de transformación social que han sido proclamadas como progresistas, participativas y democráticas.

Entendemos por pragmatismo económico cuando los gobiernos independientemente del giro ideológico de sus gobernantes, ante crisis fiscales y económicas apelan a un modelo de inserción internacional basado en la explotación de los recursos naturales (ventaja comparativa) a fin de incrementar la inversión directa extranjera y el crecimiento económico. Sin embargo, este modelo de desarrollo se interpreta principalmente en términos económicos $\mathrm{y}$ se dejan de lado los aspectos ambientales, culturales, sociales como las tensiones territoriales que se generan a escala subnacional. Debido a que las áreas de influencia directa de la minería pasan a ser como zonas sacrificables frente a las necesidades macroeconómicas del Estado Nación.

A continuación, se pueden observar sintéticamente los dos modelos de desarrollo nacional (Argentina y Ecuador) en rela- ción con la política minera (considerando que es un sector transnacionalizado), y se pueden observar algunas continuidades en términos de cómo el Estado se fue reconfigurando de acuerdo con las necesidades del capital internacional.

En el caso de Argentina, la política minera estaba vinculada al proceso de sustitución de importaciones y al desarrollo de una industria nacional. Los recursos mineros eran considerados como estratégicos y era el Estado el que lideraba el proceso productivo. Luego, con el golpe de estado en la década del '70, se comienza a desregularizar al sector y se permite el ingreso del capital internacional para exploración y explotación. Así, en la década de los noventa comienzan a explotar a gran escala las primeras transnacionales mineras en el territorio a partir de un marco legal muy favorable para las empresas, el cual se encuentra vigente hasta la actualidad. Desde entonces, las inversiones mineras no han dejado de crecer y, el país que tenía un desarrollo industrial mucho más avanzado que Ecuador, comienza un proceso de reprimarización de la economía con la minería, petróleo y la soja, destina al mercado global como materia prima. 
Ilustración 2 Modelo de Desarrollo y Política Minera Argentina

\begin{tabular}{|c|c|c|c|c|c|c|}
\hline $\begin{array}{l}\text { Modelo de } \\
\text { Desarollo - } \\
\text { ARGENTINA }\end{array}$ & $\begin{array}{l}\text { Modelo Eco- } \\
\text { nómico y de } \\
\text { Gestión Estatal }\end{array}$ & Indicadores & Modelo Minero & $\begin{array}{c}\text { Processo de Redistri- } \\
\text { bución }\end{array}$ & $\begin{array}{l}\text { Concepción so- } \\
\text { bre los Recursos } \\
\text { Naturales }\end{array}$ & $\begin{array}{l}\text { Participa- } \\
\text { ción comu- } \\
\text { nidades en } \\
\text { la toma de } \\
\text { decisiones }\end{array}$ \\
\hline $\begin{array}{l}\text { Industriali- } \\
\text { zación por } \\
\text { substitución } \\
\text { de importa- } \\
\text { ciones }\end{array}$ & $\begin{array}{l}\text { Desarrolismo. } \\
\text { El Estado como } \\
\text { planificador del } \\
\text { desarrollo. }\end{array}$ & $\begin{array}{l}\text { Modernización } \\
\text { del Estado In- } \\
\text { dustrialización }\end{array}$ & $\begin{array}{c}\text { Hasta } 1980 \text { la minería } \\
\text { estaba destinada el abaste- } \\
\text { cimiento interno y a desar- } \\
\text { rollar la indústria siderúrgi- } \\
\text { ca en el país a partir de la } \\
\text { gestión estatal. }\end{array}$ & $\begin{array}{c}\text { Generación de Cadenas } \\
\text { de Valor. } \\
\text { Cambio Social dirigido } \\
\text { desde el Estado. }\end{array}$ & $\begin{array}{l}\text { Los recursos natu- } \\
\text { rales no renovables } \\
\text { se consideraben } \\
\text { como reasseguro } \\
\text { de la soberania } \\
\text { nacional y como } \\
\text { "estratégicos" para } \\
\text { la insdustrializa- } \\
\text { ción nacional. } \\
\end{array}$ & $\begin{array}{l}\text { Sin partici- } \\
\text { pación de } \\
\text { las comu- } \\
\text { nidades en } \\
\text { el proceso } \\
\text { de toma de } \\
\text { deciosiones. }\end{array}$ \\
\hline $\begin{array}{l}\text { Neo libera- } \\
\text { lismo }\end{array}$ & $\begin{array}{l}\text { Consenso de } \\
\text { Washington. } \\
\text { Resalta la } \\
\text { macroecono- } \\
\text { mia y reduce la } \\
\text { acción estatal. } \\
\text { Modelo de la } \\
\text { Nueva Geren- } \\
\text { cia Pública. }\end{array}$ & $\begin{array}{l}\text { Crecimiento } \\
\text { Econômico. } \\
\text { Fomento de la } \\
\text { Inversión. } \\
\text { Desregulación y } \\
\text { Eficiencia en la } \\
\text { asignación del } \\
\text { gasto. Seguridad } \\
\text { jurídica. }\end{array}$ & $\begin{array}{l}\text { Inserción al mercado mega } \\
\text { minero internacional a } \\
\text { gran escala. Se genera um } \\
\text { marco legal muy ventajoso } \\
\text { al capital transnacional .La } \\
\text { ley de inversiones Mine- } \\
\text { ras limita la autonomia } \\
\text { fiscal de la provicia y los } \\
\text { municípios. Se fija el tope } \\
\text { máximo de regalias minera } \\
\text { al 3\%. 1er. Acuerdo Federal } \\
\text { Minero (coordinación de la } \\
\text { reducción fiscal). Tratado de } \\
\text { Complementación Minera } \\
\text { entre Chile y Argentina. }\end{array}$ & $\begin{array}{l}\text { Se assume que el } \\
\text { crecimiento econômi- } \\
\text { co generaria efectos } \\
\text { derrame que mejoraria } \\
\text { el bienestar de la } \\
\text { población. Además, se } \\
\text { promueve la assistência } \\
\text { de las comunidades } \\
\text { a través de la Res- } \\
\text { ponsabilidad Social } \\
\text { Empresaria }\end{array}$ & $\begin{array}{l}\text { Extractvismo } \\
\text { Clásico }\end{array}$ & $\begin{array}{l}\text { Sin partici- } \\
\text { pación de } \\
\text { las comu- } \\
\text { nidades en } \\
\text { el proceso } \\
\text { de toma } \\
\text { decisiones. }\end{array}$ \\
\hline $\begin{array}{l}\text { Populismo o } \\
\text { Nuevo De- } \\
\text { sarrolismo }\end{array}$ & $\begin{array}{c}\text { Inserción } \\
\text { Internacional } \\
\text { a través de la } \\
\text { vinculación } \\
\text { Sur-Sur. } \\
\text { Progresismo } \\
\text { Latinoameri- } \\
\text { cano. Matriz } \\
\text { política - ideo- } \\
\text { lógica Nacional } \\
\text { - Popular. }\end{array}$ & \begin{tabular}{|} 
Neo-desarrol- \\
lismo \\
Consenso de los \\
Commodites. \\
Redistribución \\
del Ingreso. \\
Universalización \\
de las políticas \\
sociales.
\end{tabular} & $\begin{array}{l}\text { Desde el Estado Nacional se } \\
\text { impulsa una organización } \\
\text { de coordinación federal em } \\
\text { matéria minera: la Organi- } \\
\text { zación Federal de Estados } \\
\text { Mineros (OFEMI). Se estab- } \\
\text { lece el 10\% de retenciones } \\
\text { a la exportación de mine- } \\
\text { rales, no copartipable alas } \\
\text { províncias y municipios. }\end{array}$ & $\begin{array}{l}\text { La redistribución se } \\
\text { plantea en términos } \\
\text { macroeconómicos, } \\
\text { a través del impulso } \\
\text { de IED que permita } \\
\text { ampliar las políticas } \\
\text { sociales a escala país, } \\
\text { es decir, la redistribu- } \\
\text { ción a las localidades } \\
\text { extractivas es relativa. }\end{array}$ & $\begin{array}{c}\text { Neo-extractivismo } \\
\text { "prograsista". } \\
\text { Los recursos } \\
\text { naturales tienem } \\
\text { um sentido ins- } \\
\text { trumental. Las } \\
\text { problemáticas } \\
\text { socio ambientales } \\
\text { son consideradas } \\
\text { como uma preocu- } \\
\text { pación secundaria } \\
\text { y sacrificable. }\end{array}$ & $\begin{array}{l}\text { Sin partici- } \\
\text { pación de } \\
\text { la comu- } \\
\text { nidades en } \\
\text { el proceso } \\
\text { de toma de } \\
\text { decisiones. }\end{array}$ \\
\hline $\begin{array}{l}\text { Nuevo Giro } \\
\text { a la Derecha }\end{array}$ & $\begin{array}{l}\text { El Estado } \\
\text { como ges- } \\
\text { tionador de } \\
\text { servicios. } \\
\text { Nueva Gober- } \\
\text { nanza. }\end{array}$ & \begin{tabular}{|} 
Limitaciones \\
a la capacidad \\
estatal para \\
amenazar \\
derechos de \\
propriedad. \\
Endeudamiento \\
Externo.
\end{tabular} & $\begin{array}{l}\text { Se provió um Nuevo } \\
\text { Acuerdo Federal Mine- } \\
\text { ro como estratégia de } \\
\text { captacion de mayores } \\
\text { inversiones em el país. Se } \\
\text { suspenden las retenciones } \\
\text { mineras. Se garantiza la } \\
\text { seguridade jurídica de las } \\
\text { empresas. }\end{array}$ & $\begin{array}{c}\text { La redistribución se } \\
\text { considera de manera } \\
\text { indirecta. Es decir, a } \\
\text { través de la genera- } \\
\text { ción de trabajo por las } \\
\text { empresas vinculadas a } \\
\text { las atividades extrac- } \\
\text { tivas. }\end{array}$ & $\begin{array}{c}\text { Se concibe al } \\
\text { extractivismo com } \\
\text { um "mal nece- } \\
\text { sario" que bien } \\
\text { administrado y } \\
\text { gestionado puede } \\
\text { Ilegar a superar } \\
\text { la primazación } \\
\text { económica. Se } \\
\text { minimizan las } \\
\text { luchas sociales } \\
\text { concentradas em } \\
\text { la defensa del ter- } \\
\text { ritório y los bienes } \\
\text { comunes. }\end{array}$ & $\begin{array}{l}\text { Sin partici- } \\
\text { pación de } \\
\text { las comu- } \\
\text { nidades em } \\
\text { el proceso } \\
\text { de toma de } \\
\text { decisiones. }\end{array}$ \\
\hline
\end{tabular}

Fuente: Elaboración Propia 
En el caso de Ecuador, el proceso de industrialización no ha sido exitoso aún en las épocas del boom petrolero. La minería como política de estado no estuvo vinculada a un proceso de industrialización nacional. Sin embargo, la minería artesanal es muy extendida en el país y no es una actividad carente de conflictos (ambientales, riesgos de derrumbe, mafias por el control del territorio, mercado en negro del oro, etc.). No obstante, de acuerdo con el inte- rés del presente articulo las inversiones en exploración en minería a gran escala son recientes, y se estima que, hacia finales del 2019, recién entraría en producción el primer yacimiento minero del país. Lo cual, hará aún más evidente las tensiones que van a emerger de la ambigüedad del marco legal en términos de regalías mineras como los conflictos socioambientales asociados a la actividad. 
Ilustración 3 Modelo de Desarrollo y Política Minera de Ecuador Fuente: Elaboración Propia

\begin{tabular}{|c|c|c|c|c|c|c|}
\hline $\begin{array}{l}\text { Modelo de Desa- } \\
\text { rollo-ECUADOR }\end{array}$ & $\begin{array}{c}\text { Modelo Económi- } \\
\text { co y de Gestión } \\
\text { Estatal }\end{array}$ & Indicadores & Modelo Minero & $\begin{array}{c}\text { Processo de Redis- } \\
\text { tribución }\end{array}$ & $\begin{array}{c}\text { Concepción sobre } \\
\text { los Recursos } \\
\text { Naturales }\end{array}$ & $\begin{array}{c}\text { Participación } \\
\text { comunidades } \\
\text { en la toma de } \\
\text { decisiones }\end{array}$ \\
\hline $\begin{array}{l}\text { Industrialización } \\
\text { por substitución } \\
\text { de importaciones } \\
\text { (década del '60) }\end{array}$ & $\begin{array}{l}\text { Desarrolismo. } \\
\text { El Estado como } \\
\text { planificador del } \\
\text { desarrollo. }\end{array}$ & $\begin{array}{l}\text { Modernización del } \\
\text { Estado; Industria- } \\
\text { lización no fue um } \\
\text { proceso exitoso }\end{array}$ & $\begin{array}{l}\text { El recurso natural } \\
\text { dominante era el } \\
\text { petróleo - Boom de } \\
\text { la resta petrolera }\end{array}$ & & $\begin{array}{c}\text { Extrativismo } \\
\text { Clásico }\end{array}$ & $\begin{array}{l}\text { Sin partici- } \\
\text { pación de las } \\
\text { comunidades } \\
\text { en el processo } \\
\text { de toma de } \\
\text { decisiones. }\end{array}$ \\
\hline Neo liberalismo & $\begin{array}{l}\text { Consenso de } \\
\text { Washington. }\end{array}$ & $\begin{array}{l}\text { Dolarización - } \\
\text { Fomento de la } \\
\text { Inversion Externa } \\
\text { Directa. }\end{array}$ & $\begin{array}{c}\text { El recurso natural } \\
\text { dominante era el } \\
\text { petroles. }\end{array}$ & & $\begin{array}{c}\text { Extractivismo } \\
\text { Clásico }\end{array}$ & $\begin{array}{l}\text { Sin partici- } \\
\text { pación de las } \\
\text { comunidades } \\
\text { em el proceso } \\
\text { de toma de } \\
\text { decisiones. }\end{array}$ \\
\hline Populismo & $\begin{array}{c}\text { Inserción Inter- } \\
\text { nacional a través } \\
\text { de la vinculación } \\
\text { Sur-Sur. } \\
\text { Progresismo Lati- } \\
\text { noamericano. } \\
\text { Matriz política } \\
\text { - ideológica del } \\
\text { Buen Vivir. Mo- } \\
\text { delo de gestión: } \\
\text { Nueva Gerencia } \\
\text { Pública. }\end{array}$ & $\begin{array}{l}\text { Neo-desarrollismo } \\
\text { Consenso de los } \\
\text { Comodities. } \\
\text { Universalización } \\
\text { de las políticas } \\
\text { sociales. }\end{array}$ & $\begin{array}{l}\text { Inserción al mercado } \\
\text { minero internacional } \\
\text { a gran escala. Se es- } \\
\text { tabelece a la minería } \\
\text { como um recurso } \\
\text { natural estratégico. } \\
\text { Mandato Minero. } \\
\text { Se cobraba regalias } \\
\text { antecipadas. La Na- } \\
\text { cional del Desarrollo } \\
\text { Minero. }\end{array}$ & $\begin{array}{l}\text { Los yacimientos } \\
\text { aún no se encuen- } \\
\text { tran em produc- } \\
\text { ción. Las regalias } \\
\text { antecipadas } \\
\text { fueron destinadas } \\
\text { a la cuentra única } \\
\text { del Tearo Nacional } \\
\text { y para luego a } \\
\text { destinarlas al } \\
\text { pressupuesto } \\
\text { nacional. }\end{array}$ & $\begin{array}{l}\text { Neo-extrativismo } \\
\text { "progressista". } \\
\text { Los recursos } \\
\text { naturales tienen } \\
\text { um sentido } \\
\text { instrumental. Las } \\
\text { problemáticas } \\
\text { socio ambienta- } \\
\text { les son conside- } \\
\text { radas como uma } \\
\text { preocupación } \\
\text { secundaria y sa- } \\
\text { crificable frente } \\
\text { a la pobreza. } \\
\end{array}$ & $\begin{array}{c}\text { Sin participa- } \\
\text { ción rel de las } \\
\text { comunidades } \\
\text { en el proceso } \\
\text { de toma de } \\
\text { decisiones. }\end{array}$ \\
\hline $\begin{array}{c}\text { Nuevo Giro a la } \\
\text { Derecha }\end{array}$ & $\begin{array}{l}\text { El Estado como } \\
\text { gestionando de } \\
\text { servicios. Modelo } \\
\text { de la Nueva } \\
\text { Governaza }\end{array}$ & $\begin{array}{c}\text { Limitaciones a la } \\
\text { capacidade estatal } \\
\text { para amenazar } \\
\text { derechos de pro- } \\
\text { priedade. } \\
\text { Endeudamiento } \\
\text { Externo. }\end{array}$ & $\begin{array}{l}\text { Bajo de categoria } \\
\text { al Ministerio de } \\
\text { Minería que passo a } \\
\text { ser Vice-Ministerio } \\
\text { dependiente del } \\
\text { Ministario de Energía } \\
\text { y Recursos Naturales } \\
\text { No renovables. Se } \\
\text { simplificaron pro- } \\
\text { cessos em licencias } \\
\text { ambientales a favor } \\
\text { de las empresas. } \\
\text { Concepción de uma } \\
\text { "minería responsable. }\end{array}$ & $\begin{array}{l}\text { Los yacimientos } \\
\text { aún no se encuen- } \\
\text { tran em pro- } \\
\text { ducción. Si bien } \\
\text { esta estabelecido } \\
\text { por ley la redis- } \\
\text { tribución de las } \\
\text { regalias mineras, } \\
\text { no hay um proce- } \\
\text { so redistributivo } \\
\text { operativo y claro } \\
\text { hacia los GADs. } \\
\text { La redistribución } \\
\text { se decir, a través } \\
\text { de la generación } \\
\text { de trabajo por las } \\
\text { empresas vincula- } \\
\text { das a las ativida- } \\
\text { des extractivas. }\end{array}$ & $\begin{array}{l}\text { Noción de um } \\
\text { Extractivismo } \\
\text { "responsable" } \\
\text { para el desarrollo } \\
\text { nacional. }\end{array}$ & $\begin{array}{c}\text { Se procuro } \\
\text { dar una mayor } \\
\text { participacion } \\
\text { a las comu- } \\
\text { nidades área } \\
\text { de influencia } \\
\text { directa, pero } \\
\text { no es um pro- } \\
\text { ceso vinculante } \\
\text { en el proceso } \\
\text { de toma de } \\
\text { decisiones } \\
\text { de la politica } \\
\text { minera. }\end{array}$ \\
\hline
\end{tabular}

Fuente: Elaboración Propia 
Con respecto a la captación de la renta minera por parte del Estado, el modelo ecuatoriano parece captar más ingresos provenientes de la actividad, pero habría que esperar que las empresas mineras comiencen a exportar para poder sacar conclusiones más fehacientes de cómo funciona el sistema redistributivo en la praxis.

Mientras, en términos de participación en el proceso de decisiones de la política minera por parte de las comunidades donde se localizan los yacimientos, en ambos países es aún tema pendiente la implementación de procedimientos claros. A pesar de ser tanto los GADs en Ecuador como los Municipios argentinos, considerados como autónomos en términos políticos, económicos e institucionales.

Al menos en Argentina, se observa que el objeto principal de disputa intergubernamental gira en torno a cómo administrar los beneficios generados por la actividad (regalías mineras u otros ingresos) y no los costes (socio ambientales). Las disputas por el manejo de la renta minera por parte de los gobiernos esta asociada al poder que se deriva del control de tales recursos.

En otras palabras, los territorios están atravesados de poder y el Estado es funcional a los intereses mineros por su alta dependencia económica, de modo que la lógica compensatoria a raíz de las consecuencias negativas del modelo productivo, son secundarias para el gobierno independientemente del modelo ideológico.

\section{Referências}

ACOSTA, A. La Maldición de la Abundancia. 1a. ed. Quito, Ecuador: Abya-Yala, Comité Ecuménico de Proyectos CEP, 2009.

BAUNSGAARD, T. A Primer on Mineral TaxationIMF Working Paper, 2001. Disponível em: <https://www.imf.org/external/pubs/ft/wp/2001/ wp01139.pdf>

BLOCK, F.; EVANS, P. El Estado y la economía. In: EVANS, P. (Ed.). Instituciones y Desarrollo en la era de la globablización neoliberal. Bogotá: ILSA, 2007. p. 307-350.

CEPAL. La Inversión Extranjera Directa, Comisión Económica para América Latina y el Caribe, Santiago de Chile, 2016.

_. Anuario estadístico de América Latina y el Caribe, 2017Publicación de las Naciones Unidas. Santiago de Chile: Naciones Unidas, 2017.

CIUFFOLINI, M. A. Contra la dominación colonial: resistencia e imaginación social versus depredación y despojo Córdoba: El Colectivo, 2012.

CIUFFOLINI, M. A.; LA VEGA, C. DE. Conflictos ambientales en América Latina: una nueva oportunidad para pensar el Estado. Claroscuro, v. X, n. 10, p. 215-237, 2011.

COLOMER, J. Instituciones Políticas. Barcelona: Ariel, 2001.

CORONIL, F. Naturaleza del poscolonialismo: del eurocentrismo al globocentrismo. In: LANDER, E. (Ed.). . La colonialidad del saber: eurocentrismo y ciencias sociales, perspectivas latinoamericanas. Buenos Aires: CLACSO, 2003. p. 248.

DEMIROVIC, A.; HIRSCH, J.; JESSOP, B. Einleitung der Herausgeber. In: Nicos Poulantzas. Staatstheorie. Politischer Uberbau, Ideologie, Autoritärer Estatismus. Hamburgo: VSA, 2002. p. 7-32.

ESPINOZA, I. V. El enfoque estratégico-relacional: implicancias para el estudio del Estado, las instituciones y el desarrollo en América Latina. Iquique: Facultad de Ciencias Humanas, Universidad Arturo Prat., 2014.

EVANS, P.; SEWELL, W. H. Neoliberalism: Policy Regimes, International Regimes, and Social Effects. In: HALL, P.; LAMONT, M. (Eds.) Social Resilience in the Neo-Liberal Era. Cambridge: Cambridge University Press, 2013. .

FOUCAULT, M. Seguridad, Territorio, Poblacion: Curso en el Collége de France: 1977-1978. Bue- 
nos Aires: Fondo de Cultura Económica, 2006.

GAMBINA, J. C.; LIZUAIN, A.; PAPI, S. Consideraciones sobre la cuestión minera en Argentina. Mexico: Universidad Nacional Autónoma de México. Centro de Investigaciones Interdisciplinarias en Ciencias y Humanidades, 2010.

GIBSON, E. Federalism and Democracy in Latin America. Baltimore and London: The Johns Hopkins University Press, 2004.

HAESBAERT, R. 0 mito da desterritorializacao: do 'fin dos territorios' á multiterritorilidades. 6ta. ed. Rio de Janeiro: Bertrand Brasil, 2011.

HARVEY, D. The new imperialism. Nueva York: Oxford University Press, 2003.

ITURBURU, M. S. Municipios Argentinos. Fortalezas y debilidades de su diseño institucional. Buenos Aires: [s.n.].

JESSOP, B. State Power. Cambridge, Inglaterra: Polity Press, 2007.

El Estado y el poder. Utopía y Praxis Latinoamericana, v. 19, n. 66 (Julio-Septiembre), p. 19-35, 2014.

LATORRE, S.; SANTILLANA, A. Capitalismo estatal o convergencias populares. Revista de Ciencias Sociales ICONOS, v. 13, n. 34, p. 13-18, 2009.

OLMEDA, J. C. De Menen a Kirchner: relaciones intergubernamentales y patrones de negociación en el federalismo fiscal argentino. In: El federalismo argentino en perspectiva comparada. Córdoba: EDUCC- Editorial de la Universidad Católica de Córdoba, 2012. p. 159-197.

PAZ, A. Los desafíos ambientales para 2019.

Disponivel em: <https:/gk.city/2019/01/11/ problemas-ambientales-ecuador-2019/>.

PRADO, 0. Situación y Perspectivas de la minería metálifera en Argentina. Santiago de Chile: CEPAL, 2005.

RADHUBER, I. M. Los recursos naturales y finanzas públicas. La base material del Estado plurinacional de Bolivia. La Paz, Bolivia: Plural editores, 2014. REA, A. Política minera y sostenibilidad ambien- tal en Ecuador. Figempa: Investigación y Desarrollo, v. 2, n. 2, p. 41-52, 2017.

RIKER, W. European Federation: Lessons of Past Experience. In: Federalizing Europe: the cost, benefits and preconditions of federal political systems. Oxford: Oxford University Press, 1996. . ROBINSON, W. Una teoría sobre el capitalismo global. Producción, clase y Estado en un mundo transnacional. Mexico,: Siglo XXI, 2013.

SAGUIER, M.; PEINAD0, G. Minería transnacional y desarrollo en el kirchnerismo. INTERNATIONAL CONFERENCE GLOBAL AND REGIONAL POWERS IN A CHANGING WORLD. Anais... Buenos Aires : FLACSO - ISA, 2015.

SANTOS, M. A Natureza do Espaço: Técnica e Tempo, Razão e Emoção, 4. ed. São Paulo: Editora da Universidade de São Paulo, 2006.

SASSEN, S. Territorio, autoridad y derechos: de los ensamblajes medievales a los ensamblajes globales. Madrid: Katz Editores, 2010.

SCHWEITZER, A. Desarrollando el desierto. Procesos de frontera en la provincia de Santa Cruz. Revista de Ciencias Sociales, v. 00, n. 24, p. 51-69, 2013.

La Patagonia sur como espacio global para la expansión del capital transnacional. Revista Theomai, v. 34, n. 34, p. 139-151, 2016.

SILVEIRA, M. et al. Geografías de sacrificio y geografías de esperanza : tensiones territoriales en el Ecuador plurinacional. Journal of Latin American Geography, v. 16, n. 1, p. 69-92, 2016. SVAMPA, M. El Consenso de los Comodities. p. 4-6, 2013a.

. "Consenso de los Commodities " y lenguajes de valoración en América Latina. Nueva Sociedad, v. 244, p. 30-46, 2013b.

THWAITES REY, M. Después de la globalización neoliberal: ¿Qué Estado en América Latina? Buenos Aires, CLACSO, 2010.

TILLY, C. Prisoners of the State, New York, 1991. 


\section{RESUMEN}

La expansión de las fronteras extractivas por la explotación minera genera una contradicción entre la razón global y la local. En tal sentido, el Estado Nacional asume un rol ambiguo y de permanente tensión entre la fusión de acumulación (inserción internacional) y la legitimidad estatal, en particular, ante la resistencia de los movimientos sociales frente a relaciones sociales desiguales, excluyentes y no democráticas que se presentan en los escenarios locales. Cabe destacar que los recursos naturales se encuentran enclavados espacialmente, y si bien su explotación es de interés nacional, el proceso extractivo afecta a la vida y los entornos locales. Por ello, en el presente artículo se pretende analizar la trayectoria de la política redistributiva minera de manera comparativa entre dos modelos de Estados (federal y unitario), en dos países con políticas mineras distintas: Argentina y Ecuador.

\section{PALABRAS CLAVES}

Política minera. Estado. Relaciones intergubernamentales. Regalías mineras.

\section{RESUMO}

A expansão das fronteiras extrativistas pelo modelo extrativista de mineração gera uma contradição entre a razão global e local. A este respeito, o governo nacional assume um papel ambíguo e de permanente tensão entre a fusão de acumulação (inserção internacional) e a legitimidade do Estado, em particular, frente a resistência dos movimentos sociais contra as relações sociais desiguais, excludentes e antidemocráticas que aparecem em cenários locais. Cabe destacar que os recursos naturais estão espacialmente interligados e, embora sua exploração seja de interesse nacional, o processo extrativo afeta a vida e a sociedade local. Por tanto, neste artigo pretendemos analisar a natureza da política redistributiva de mineração comparando dois modelos de Estados (federais e unitário) em dois países com diferentes trajetórias de mineração: Argentina e Equador.

\section{PALAVRAS-CHAVE}

Política de mineração. Estado. Relações intergovernamentais. Royalties de mineração. 


\section{ABSTRACT}

The expansion of Mining's extractive borders generates a contradiction between the global and local reasons. Thereby, the National State assumes an ambiguous role of permanent tension between the fusion of accumulation (inclusion international) and State legitimacy, in particular, against the resistance of social movements facing unequal social relations, exclusionary and nondemocratic that occur in local scenarios. It should be noted that the natural resources are spatially interlocked, and although their exploitation is of national interest, the extractive process affects local life and environments. Therefore, this article aims to analyze the trajectory of redistributive mining policy in a comparative way between two States (federal and unitary) models, in two countries with different mining paths: Argentina and Ecuador.

\section{KEY WORDS}

Mining policy. Intergovernmental relations. State and mining royalties. 